\title{
A novel decision aid to help plan for serious illness: a multisite randomized trial
}

\author{
Daren K. Heyland MD MSc, Rebecca Heyland BSc, Alice Bailey MBBCh BAO, \\ Michelle Howard MSc PhD
}

Abstract

Background: Recent studies have shown substantial deficiencies in the quality or quantity (or both) of communication and decisionmaking during serious illness. We evaluated the efficacy of a novel decision support intervention, the Plan Well Guide, in increasing completion of a standard medical order form for advance medical care planning and improving decisional outcomes in nonacademic primary care settings.

Methods: We conducted a randomized trial in 3 primary care practices in Lethbridge, Alberta in 2017-2018. We recruited "patients at high risk" referred by the primary care doctor who required establishment or review of their Goals of Care Designation (GCD). Enrolled patients were randomly allocated to receive the Plan Well Guide, delivered by a trained facilitator, or usual care. Eight to 12 weeks after the intervention, a research assistant blinded to intervention assignment contacted the patients in both groups by telephone to do a final outcome assessment. The primary outcome was completion of GCD forms; secondary outcomes included decisional conflict scores and ratings of satisfaction.

Results: A total of 123 patients (59 women [48.0\%]; mean age $73.9 \mathrm{yr}$ ) were enrolled, 66 in the intervention arm and 57 in the usualcare arm; 119 patients completed the trial. After the intervention, GCD completion rates in the intervention and usual-care groups were $95.3 \%$ and $90.9 \%$, respectively (risk difference [RD] $4 \%, 95 \%$ confidence interval $[\mathrm{Cl}]-14 \%$ to $22 \%$ ), and the rate of concordance between medical orders and expressed preferences on follow-up was $78 \%$ and $66 \%$, respectively (RD $12 \%, 95 \% \mathrm{Cl}-7 \%$ to $30 \%)$. Significantly fewer patients in the intervention group than in the usual-care group had written medical orders for intensive care unit care and cardiopulmonary resuscitation (22 [34\%] v. 33 [60\%], RD $-26 \%, 95 \% \mathrm{Cl}-42 \%$ to $-8 \%$ ). Patients in the intervention group had lower decisional conflict scores than those in the usual-care group (mean 30.9 v. 43.1, adjusted mean difference -12.0 , $95 \% \mathrm{Cl}-23.2$ to -0.8 ). Physicians considered patients in the intervention group to have lower decisional conflict than those in the usual-care group, although not significantly so (mean score $10.4 \mathrm{v} .14 .9$, adjusted mean difference $-4.7,95 \% \mathrm{Cl}-9.9$ to 0.4 ) and spent less time with the former (mean 9.7 v. $13.2 \mathrm{~min}$, adjusted mean difference $-3.5,95 \% \mathrm{Cl}-5.5$ to $-1.5 \mathrm{~min}$ ).

Interpretation: The decision-support intervention did not increase GCD completion rates but did seem to improve some aspects of decisional quality while reducing the physician's time to accomplish GCD decisions. Trial registration: ClinicalTrials.gov, no. NCT01297946

everal recent studies have shown substantial deficiencies in the quality or quantity (or both) of communication and decision-making during serious illness. ${ }^{1-6} \mathrm{~A}$ major problem is that doctors infrequently engage in such conversations with seriously ill patients because they believe patients are ill-prepared to have such conversations. ${ }^{7,8}$ Research conducted by our group showed considerable discordance between older patients' stated values and their preferences related to the use of life-sustaining treatments, and a considerable lack of knowledge and understanding regarding cardiopulmonary resuscitation, a key medical decision for patients admitted to hospital. ${ }^{9-11}$ We concluded that more efforts to increase the "decisional readiness" of seriously ill patients (and their families) were warranted before health care professionals can be expected to engage them in high-quality conversations that will improve clinical decision-making in the context of serious illness.
Accordingly, we developed a novel decision aid, the Plan Well Guide, with the express aim of helping patients clarify their authentic values and be truly informed about the medical treatment options in the context of serious illness. We aimed to evaluate the efficacy of the guide in primary care settings, before the onset of serious illness. Our overarching hypothesis was that the use of this decision aid in older patients in primary care will result in increased quantity and quality of subsequent planning decisions with primary care physicians compared to usual care.

\section{Competing interests: None declared.}

This article has been peer reviewed.

Correspondence to: Daren Heyland, dkh2@queensu.ca

CMAJ Open 2020. DOI:10.9778/cmajo.20190179 


\section{Methods}

\section{Design}

This was a prospective multicentre, patient-based, pragmatic, assessor-blinded, parallel-group, randomized clinical trial conducted from September 2017 to October 2018. The trial was registered, but, owing to an administrative error, registration occurred after the trial began (Clinicaltrials.gov NCT03434626).

\section{Setting}

We partnered with 3 nonacademic primary care settings in Lethbridge, Alberta. A province-wide standard medical order form, Goals of Care Designation (GCD) (https://www. albertahealthservices.ca/frm-103547.pdf), is used in Alberta for physicians to indicate the level of care a patient is to receive when seriously ill (resuscitative or intensive care, medical care or comfort care). To facilitate the trial, we set up a special GCD clinic in each practice setting where research staff met with referred patients.

\section{Participants}

We aimed to enrol "patients at high risk" considered by the primary care physician to require establishment or review of the GCD form because of a perceived high probability of hospital admission. No specific inclusion criteria were established, but guidelines from the study team included any patient aged 75 or more; any patient with a complex care plan or complicated, serious, life-threatening illnesses; any patient with a serious illness following a recent hospital stay for whom it was felt that GCD review would be appropriate; any patient whose death in the subsequent 12 months would not surprise the physician; and any other patient for whom the physician thought it appropriate to start the advance care planning discussion or review past discussions. Patients who did not speak English were excluded from the trial.

Participating doctors referred potentially eligible patients to the GCD clinic. Patients were provided with a workbook on advance care planning (Speak Up Workbook) and were encouraged to complete the workbook before their GCD clinic appointment. At the appointment, an expert GCD facilitator (D.K.H., R.H., or 1 of 2 research staff) explained the nature of the trial, randomly assigned consenting patients to the intervention or usual care group, and collected basic demographic data. All GCD facilitators participated in faceto-face training led by the principal investigator (D.K.H.).

Our randomization process used sequentially numbered, opaque sealed envelopes prepared by a biostatistician otherwise uninvolved in study management or patient recruitment. Patients were randomly allocated $(1: 1)$ to receive the decision support intervention or usual care. Randomization used permuted blocks of varying size $(2,4$ or 8 , previously undiscussed) stratified by the facilitator. We enrolled 31 couples (husband and wife); when this occurred, we used the same treatment allocation for both members of the couple.

Written informed consent was obtained from all patients, and verbal consent was obtained from participating physicians.

\section{Intervention}

The process to develop and initially evaluate the Plan Well Guide decision support intervention is described in more detail in Appendix 1 (available at www.cmajopen.ca/content/ 8/2/E289/suppl/DC1). To deploy the intervention in this trial, we created a Microsoft PowerPoint presentation with audio explanations of the content to enable a structured, consistent delivery of the material to participating patients.

For patients randomly allocated to the intervention group, the facilitator walked the patient through the Plan Well Guide presentation. At the end of the presentation, the facilitator worked with the patient to fill out the "Dear Doctor" letter (Appendix 2, available at www.cmajopen.ca/content/8/2/E289/ suppl/DC1) and coached the patient to communicate his or her values and preferences to the referring doctor via this letter. The patient was then referred back to the family doctor for review of the Dear Doctor letter and finalization of the GCD. At this point, the participating doctor filled out the physician assessment form, which elicited his or her perceptions of the effect of the intervention on the patient (Appendix 3, available at www.cmajopen.ca/content/8/2/E289/suppl/DC1), and returned it to the facilitator.

If the patient was assigned to usual care, after filling out baseline forms, the facilitator instructed the patient to return to see the referring doctor for finalization the GCD. No supplementary information was provided to prepare the patient for the conversation with the doctor about GCD. The physician then completed the assessment form and returned it to the facilitator.

\section{Outcomes}

The outcomes of this trial included prespecified measures of decisional quality and quantity, and were consistent with a recent international consensus statement on outcomes of advance care planning. ${ }^{12}$ The primary outcome was the proportion of patients who had a completed and signed GCD form in the patient chart 8-12 weeks after the intervention.

Secondary outcomes included the nature of the medical orders (the level of medical care specified, i.e., for resuscitation or not) and the extent to which the order was consistent with the patient's expressed preferences (concordance measure); a short screening test administered to the patient to assess decisional conflict ${ }^{13}$ relating to his or her preference for life-sustaining treatments, modified for the context of decision-making in serious illness (rated on a scale of 0 to 100 ; lower score = less decisional conflict); a single-item, global rating of satisfaction with decision-making for both participants and physicians; physician ratings of the patient's decisional conflict (Appendix 3); and the amount of time the physician spent with the patient finalizing goals of care.

Eight to 12 weeks after the intervention, a research assistant from the Clinical Evaluation Research Unit at the Kingston General Hospital (research unit of D.K.H.) who was blinded to intervention assignment contacted the patients in both groups via telephone to do a final assessment of their GCD and decisional conflict. During the same period, local research staff audited clinic charts to determine the presence and content of GCDs in the patients' charts. 


\section{Sample size}

Rates of GCD completion in the average family practice setting are low $(<10 \%) .{ }^{14}$ However, given that our participants were selected patients referred to a GCD consultation clinic, we expected the completion rate in the control group to be much higher. To achieve $80 \%$ power to detect an absolute improvement of $25 \%$ (from $60 \%$ to $85 \%$ ) or $20 \%$ (from $75 \%$ to $95 \%$ ) using a Fisher exact test with 2 -sided $\alpha=0.05$, we would need follow-up assessments for 55 patients per arm. We thus aimed to enrol 120 patients, to allow for loss to follow-up or imbalance between arms.

\section{Statistical analysis}

We determined patient characteristics and outcomes by group using descriptive statistics (counts and percentage, or mean and standard deviation and quartiles for highly skewed variables). When calculating agreement between preferences and documented goals of care, we omitted patients with missing data and those who expressed uncertainty about their preference regarding goals of care. In addition, we reported concordance rates as the proportion of patients whose preferences to receive or not to receive cardiopulmonary resuscitation, elicited during the interview, were consistent with their documented preference for cardiopulmonary resuscitation on their GCD forms in their charts.

We tested between-group differences of binary outcomes including completion of the GCD form, desired goals of care, and agreement between preferences and documented goals of care (concordance measure) using the Fisher exact test and described them using risk differences with exact $95 \%$ confidence intervals (CIs). We used the exact Cochran-Armitage test for trend to compare the ordinal decisional conflict items between groups. For all continuous variables, including the overall decisional conflict score and time spent with patients finalizing goals of care, the adjusted mean difference between arms was estimated by means of a 2-way analysis of variance controlling for site. The analysis was performed in SAS version 9.4 (SAS Institute). No adjustment was made for multiplicity of outcomes.

\section{Ethics approval}

The project was approved by the Hamilton Integrated Research Ethics Board.

\section{Results}

From September 2017 to October 2018, 163 patients were referred to the trial, of whom 123 consented and were randomly assigned to the intervention $(n=66)$ or usual-care $(n=$ 57) group (Figure 1). Of the 123, 98 (79.7\%) were married, and $64(52.0 \%)$ were male; the average age was 73.9 years. There were no important differences in baseline characteristics between the 2 groups (Table 1).

Following the baseline and intervention visits, 121 patients returned to see their referring physician to discuss and complete a GCD form. Compared to the usual-care patients, those in the intervention group were rated by their physician

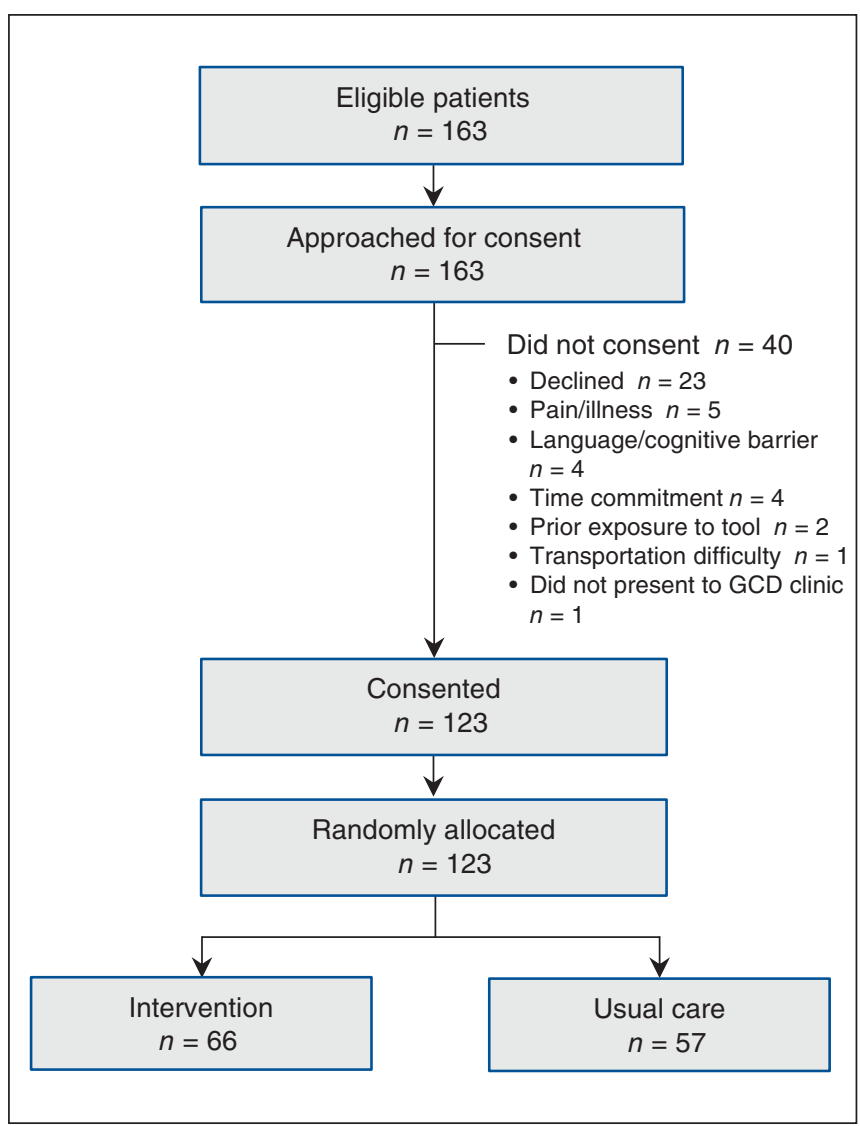

Figure 1: Flow diagram showing patient selection. Note: GCD = Goals of Care Designation.

as having lower decisional conflict, although not significantly so (mean score 10.4 [standard deviation (SD) 11.7] v. 14.9 [SD 16.9], adjusted mean difference -4.7 [95\% CI -9.9 to 0.4$]$ ) (Table 2, Figure 2). The items that constitute the decisional conflict score consistently favoured the intervention group, although only clarity about which risks and benefits matter most reached statistical significance; there were trends toward statistical significance for improved knowledge and enough information and support from the medical team (Figure 2).

Patients in the intervention group reported lower decisional conflict than those in the usual-care group (mean score 30.9 [SD 26.1] v. 43.1 [SD 32.8], adjusted mean difference $-12.0,95 \%$ CI -23.2 to -0.8$)$. Patients in the intervention group reported lower decisional conflict than those in the usual-care group (mean score 30.9 [SD 26.1] v. 43.1 [SD 32.8], adjusted mean difference $-12.0,95 \% \mathrm{CI}-23.2$ to -0.8$)$. The difference between groups was statistically significant for being clear what matters the most, having more support and information from the primary care team, and feeling more sure that their selected option is best for them (Figure 2).

On average, physicians spent less time finalizing goals of care for patients in the intervention group than for those in the usual-care group (mean 9.7 [SD 5.4] min v. 13.2 [SD 5.0] min; adjusted mean difference $-3.5,95 \% \mathrm{CI}-5.5$ to $-1.5 \mathrm{~min}$ ). Physicians reported being completely or somewhat satisfied with the clinical encounter in 106 cases $(86.2 \%)$. 


\begin{tabular}{|c|c|c|c|}
\hline \multirow[b]{2}{*}{ Characteristic } & \multicolumn{3}{|c|}{ Group; no. (\%) of patients* } \\
\hline & $\begin{array}{c}\text { Intervention } \\
n=66\end{array}$ & $\begin{array}{c}\text { Usual care } \\
n=57\end{array}$ & $\begin{array}{l}\text { Overall } \\
n=123\end{array}$ \\
\hline Age, yr, mean \pm SD & $73.5 \pm 15.9$ & $74.4 \pm 11.1$ & $73.9 \pm 13.9$ \\
\hline \multicolumn{4}{|l|}{ Sex } \\
\hline Male & $33(50.0)$ & $31(54.4)$ & $64(52.0)$ \\
\hline Female & $33(50.0)$ & $26(45.6)$ & $59(48.0)$ \\
\hline \multicolumn{4}{|l|}{ Current marital status } \\
\hline Married/living as married & $54(81.8)$ & $44(77.2)$ & $98(79.7)$ \\
\hline Widowed & $9(13.6)$ & $8(14.0)$ & $17(13.8)$ \\
\hline Never married & $2(3.0)$ & $4(7.0)$ & $6(4.9)$ \\
\hline Divorced/separated; not remarried & $1(1.5)$ & $1(1.8)$ & $2(1.6)$ \\
\hline \multicolumn{4}{|l|}{ Highest level of education completed } \\
\hline Did not complete secondary school & $18(27.3)$ & $10(17.5)$ & $28(22.8)$ \\
\hline Completed secondary school & $7(10.6)$ & $9(15.8)$ & $16(13.0)$ \\
\hline $\begin{array}{l}\text { Some university education, or } \\
\text { completed community college, } \\
\text { technical college or postsecondary } \\
\text { program }\end{array}$ & $25(37.9)$ & $27(47.4)$ & $52(42.3)$ \\
\hline University degree & $12(18.2)$ & $5(8.8)$ & $17(13.8)$ \\
\hline Graduate degree & $4(6.1)$ & $6(10.5)$ & $10(8.1)$ \\
\hline \multicolumn{4}{|l|}{ Self-rated overall quality of life } \\
\hline Excellent & $8(12.1)$ & $8(14.0)$ & $16(13.0)$ \\
\hline Very good & $29(43.9)$ & $32(56.1)$ & $61(49.6)$ \\
\hline Good & 22 (33.3) & $12(21.0)$ & $34(27.6)$ \\
\hline Fair & $6(9.1)$ & $3(5.3)$ & $9(7.3)$ \\
\hline Poor & $1(1.5)$ & $2(3.5)$ & $3(2.4)$ \\
\hline \multicolumn{4}{|l|}{$\begin{array}{l}\text { Needs help when reading instructions, } \\
\text { pamphlets or other written material } \\
\text { from doctor or pharmacy }\end{array}$} \\
\hline Never & $36(54.5)$ & $32(56.1)$ & 68 (55.3) \\
\hline Occasionally & $20(30.3)$ & $16(28.1)$ & $36(29.3)$ \\
\hline Sometimes & 7 (10.6) & $3(5.3)$ & $10(8.1)$ \\
\hline Often & $1(1.5)$ & $3(5.3)$ & $4(3.2)$ \\
\hline Always & $2(3.0)$ & $3(5.3)$ & $5(4.1)$ \\
\hline
\end{tabular}

Four patients ( 2 in either group) could not be contacted for the follow-up assessment; thus, 119 patients were included in the final analysis. The rate of completion of the GCD form was higher than expected in both groups, and rates were not different between the groups $(95.3 \%$ in intervention group v. $90.9 \%$ in usual-care group, risk difference [RD] 4\%, $95 \%$ CI $-14 \%$ to $22 \%$ ) (Table 3 ). However, fewer patients in the intervention group than in the usual-care group had a GCD that would lead to provision of cardiopulmonary resuscitation and intensive care unit care (22 [34\%] v. 33 [60\%], RD -26\%, $95 \%$ CI $-42 \%$ to $-8 \%)$.
The crude agreement between the medical order recorded in the GCD form and the patient's expressed preference on follow-up was higher in the intervention group than in the usual-care group, but the difference was not statistically significant ( $56 \%$ v. $46 \%$, RD $10 \%, 95 \%$ CI $-9 \%$ to $28 \%$ ). Similarly, there was no significant difference between groups in concordance between ordered care and patient preference on follow-up to receive or not to receive cardiopulmonary resuscitation ( $78 \%$ v. $66 \%$, RD $12 \%, 95 \% \mathrm{CI}-7 \%$ to $30 \%$ ).

Forty-six patients $(72 \%)$ were very satisfied with the decision support intervention, and $55(86 \%)$ said they 
Table 2: Physician and patient assessment of patient's decisional conflict in the $\mathbf{2}$ groups

\begin{tabular}{|c|c|c|}
\hline \multirow[b]{2}{*}{ Decisional conflict item } & \multicolumn{2}{|c|}{ Group; mean raw score \pm SD* } \\
\hline & Intervention & Usual care \\
\hline \multicolumn{3}{|l|}{$\begin{array}{l}\text { Physician assessment of } \\
\text { decisional conflict }\end{array}$} \\
\hline Knows benefits and risks & $13.8 \pm 21.1$ & $20.8 \pm 24.6$ \\
\hline Clear what matters most & $11.0 \pm 14.6$ & $18.4 \pm 22.0$ \\
\hline $\begin{array}{l}\text { Has enough support and advice } \\
\text { from family }\end{array}$ & $7.6 \pm 14.5$ & $10.2 \pm 17.2$ \\
\hline $\begin{array}{l}\text { Has enough support and } \\
\text { information from primary care } \\
\text { team }\end{array}$ & $7.2 \pm 12.2$ & $12.3 \pm 21.2$ \\
\hline Feels SURE & $12.7 \pm 17.3$ & $13.2 \pm 17.4$ \\
\hline Overall decisional conflict & $10.4 \pm 11.7$ & $14.9 \pm 16.9$ \\
\hline \multicolumn{3}{|l|}{$\begin{array}{l}\text { Patient assessment of } \\
\text { decisional conflict }\end{array}$} \\
\hline Knows benefits and risks & $36.9 \pm 40.3$ & $43.3 \pm 39.9$ \\
\hline Clear what matters most & $25.8 \pm 31.8$ & $41.3 \pm 37.7$ \\
\hline $\begin{array}{l}\text { Has enough support and advice } \\
\text { from family }\end{array}$ & $44.5 \pm 42.3$ & $50.5 \pm 40.8$ \\
\hline $\begin{array}{l}\text { Has enough support and } \\
\text { information from primary care } \\
\text { team }\end{array}$ & $29.7 \pm 34.3$ & $46.0 \pm 38.3$ \\
\hline Feels SURE & $17.8 \pm 27.5$ & $31.9 \pm 36.1$ \\
\hline Overall decisional conflict & $30.9 \pm 26.1$ & $43.1 \pm 32.8$ \\
\hline \multicolumn{3}{|c|}{$\begin{array}{l}\text { Note: } \mathrm{SD}=\text { standard deviation, SURE = Sure of myself, Understand information, } \\
\text { Risk-benefit ratio, Encouragement. } \\
\text { *On a scale of } 0 \text { to } 100 \text {; lower score = less decisional conflict. }\end{array}$} \\
\hline
\end{tabular}

would definitely or probably recommend the program to others (Table 3).

\section{Interpretation}

In this randomized trial of a novel decision aid for advance medical care planning in nonacademic primary care settings, GCD completion rates were high in both groups, and rates were not different between groups. Nevertheless, compared to usual care, this intervention reduced orders for intensive care unit care and cardiopulmonary resuscitation, reduced decisional conflict, increased patient knowledge of medical decisions, helped clarify patients' values and gave patients increased confidence in engaging health care professionals about their GCD. Physicians reported being satisfied with the decision-making process and spent less time with patients who had received the decision support intervention than with those who received usual care.

Our findings are consistent with other randomized trials of patient decision support tools or advance care planning interventions that have shown that these planning or preparing interventions affect patient and health system outcomes positively. ${ }^{15-20}$ However, prior studies were conducted in hospital ${ }^{17}$ or academic outpatient settings, ${ }^{18,19}$ or were Internet-based. ${ }^{16}$
In an attempt to broaden the generalizability of these prior studies and influence care before the onset of serious illness, we worked in nonacademic primary care settings to conduct this practice-based research.

Although there are many existing tools for advance care planning available, there are several features of our decision support intervention that make it particularly useful for patients and clinicians (Appendix 1, Box 1). In our experience, patients have difficulty discriminating between planning for terminal care and planning for medical care when seriously ill, and our decision support tool specifically addresses these differences. One of the other key observations from the development process was the difficulty patients had linking their underlying values to their preferences for medical treatments. Accordingly, we developed a short values-clarification tool that made the trade-offs between common end-of-life values very transparent and then connected the values scales to the grids shown in Appendix 1, Supplemental Figure S2 to make this process transparent.

Myers $^{21}$ has argued that clinicians should elicit goals of care only in terms that are meaningful to the patient, which are a reflection of their personal values and priorities, such as to remain alive to attend a daughter's wedding or to remain independent. Although these impressions may be helpful in decision-making, many clinicians then translate these broad, patient-centred statements into specific medical decisions about which treatments to use or not to use in the context of serious illness, without further patient input. ${ }^{22}$ Such an approach may be biased, lacks transparency and reliability, and, in our view, perpetuates a power imbalance that may be a major barrier to shared decision-making approaches. ${ }^{23-27}$ The Plan Well Guide explains decision-making in the context of serious illness, helps patients clarify their authentic values through constrained values-clarification approaches and educates patients about the different levels of medical care available when seriously ill, and then transparently connects patient values to treatment preferences.

We have previously reported low rates of agreement between patients' expressed preferences and their goals of care documented in the medical chart in an inpatient population, with most of the disconnect related to overuse of cardiopulmonary resuscitation. ${ }^{7}$ In the current study, patients in the intervention group were much less likely than those in the usual-care group to express a preference for cardiopulmonary resuscitation. Given this finding, along with the fact that the decision support intervention reduced physician time in decision-making, the intervention may have important economic implications.

To date, this decision aid has been implemented with trained, expert facilitators. We have developed a Web-based version of the tool in which a patient can go through the materials independent of a facilitator (https://planwellguide.com).

\section{Limitations}

Strengths of this project include the rigour with which the decision aid was developed and evaluated, concealed randomized blinded assessment of patient outcomes, and limited loss 


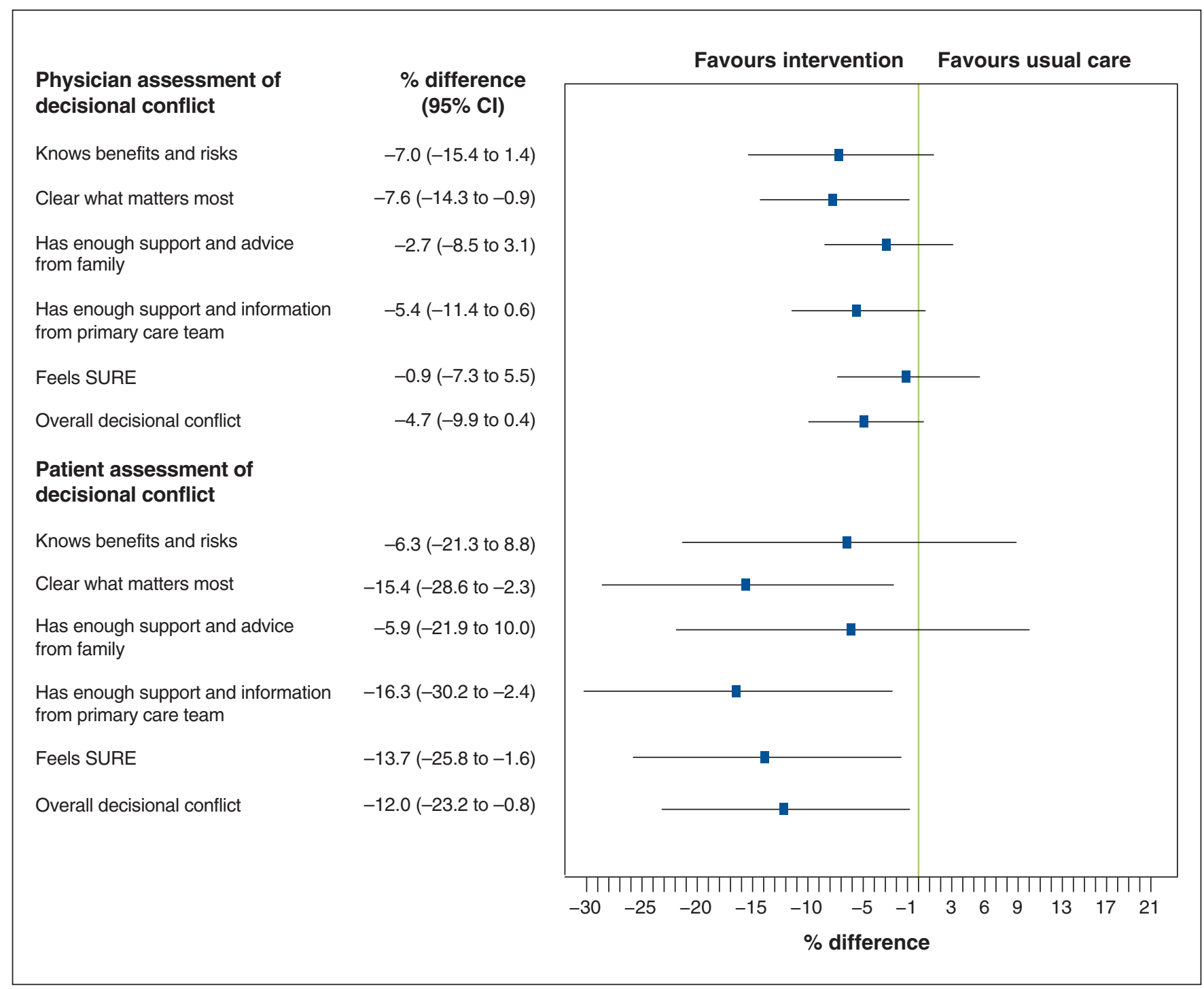

Figure 2: Point estimates of difference in decisional conflict between patients in the decision-support intervention and usual-care groups. Error bars represent $95 \%$ confidence interval $(\mathrm{Cl})$. Note: SURE = Sure of myself, Understand information, Risk-benefit ratio, Encouragement.

to follow-up. A limitation of this trial is the small sample, which resulted in imprecise estimates for many of the outcome comparisons and limited the ability to conduct subgroup analyses. Moreover, the small sample of patients from a limited geographic area, all English speakers, limits the generalizability of the findings. No specific inclusion criteria were used, which may limit the reproducibility of the trial; however, it also enhances the validity of the real-world findings. The lack of patient and physician blinding to intervention assignment is an additional limitation.

The rate of completed and signed GCD forms in the patient chart was much higher than expected in the control arm, which left little room for improvement from the intervention. It may be that clinicians referred only patients motivated to engage in GCD conversations, or the nature of the study design, with a protocolized follow-up appointment with the referring physician, may explain this finding. Also, all study patients received materials related to advance care planning, which may have further motivated them to complete their GCD. These factors likely combine to minimize the impact of the intervention and call into question the potential effect of the intervention in a broader, unselected population with less rigorous follow-up.

Finally, using the same treatment allocation for both members of couples induced a potential correlation between responses for a substantial portion of the sample. Accounting for this would further widen the CIs.

\section{Conclusion}

The decision support intervention had no impact on rates of completion of GCD forms in primary care. However, it seemed to help patients clarify values and better inform them regarding the medical treatment options available when seriously ill, and may reduce their preference for resuscitation. The decision support aid reduced physician barriers to engaging their patients by reducing the time spent on these important discussions. The aid has the potential to improve the 
Table 3: Telephone follow-up assessment in the 2 groups

\begin{tabular}{|c|c|c|c|c|}
\hline \multirow[b]{2}{*}{ Item } & \multicolumn{3}{|c|}{ Group; no. (\%) of patients } & \multirow[b]{2}{*}{$p$ value } \\
\hline & $\begin{array}{l}\text { Intervention } \\
\quad n=64\end{array}$ & $\begin{array}{c}\text { Usual care } \\
n=55\end{array}$ & $\begin{array}{l}\text { Overall } \\
n=119\end{array}$ & \\
\hline Preferences on follow-up & & & & 0.4 \\
\hline $\begin{array}{l}\text { Use machines and all possible measures including resuscitation } \\
\text { (CPR) with a focus on keeping me alive at all costs }\end{array}$ & $10(15.6)$ & $16(29.1)$ & $26(21.8)$ & \\
\hline $\begin{array}{l}\text { Use machines and all possible measures with a focus on keeping me } \\
\text { alive, but if my heart stops, no resuscitation (CPR) }\end{array}$ & $5(7.8)$ & $2(3.6)$ & $7(5.9)$ & \\
\hline $\begin{array}{l}\text { Use machines only in the short term to see if I will get better, but if the } \\
\text { illness is prolonged, change focus to comfort measures only; if my } \\
\text { heart stops, no resuscitation (CPR) }\end{array}$ & $29(45.3)$ & $19(34.5)$ & $48(40.3)$ & \\
\hline $\begin{array}{l}\text { Use full medical care to prolong my life, but if my heart or my breathing } \\
\text { stops, no resuscitation (CPR) or breathing machines }\end{array}$ & $6(9.4)$ & $5(9.1)$ & $11(9.2)$ & \\
\hline $\begin{array}{l}\text { Use comfort measures only with a focus on improving my quality of life } \\
\text { and comfort; allow natural death, and no artificial prolongation of life } \\
\text { and no resuscitation (CPR) }\end{array}$ & $11(17.2)$ & $10(18.2)$ & $21(17.6)$ & \\
\hline Unsure & $2(3.1)$ & $0(0.0)$ & $2(1.7)$ & \\
\hline Missing & $1(1.6)$ & $3(5.4)$ & $4(3.4)$ & \\
\hline Completeness of GCD in patient's Green Sleeve* & & & & 0.47 \\
\hline Completed & $61(95.3)$ & $50(90.9)$ & $111(93.3)$ & \\
\hline Not completed & $3(4.7)$ & $5(9.1)$ & $8(6.7)$ & \\
\hline $\begin{array}{l}\text { Goal of care on (GCD) form in your Green Sleeve* from telephone } \\
\text { assessment }\end{array}$ & & & & 0.03 \\
\hline Intensive care including CPR & $22(34.4)$ & $33(60.0)$ & $55(46.2)$ & \\
\hline Intensive care excluding CPR & $21(32.8)$ & $10(18.2)$ & $31(26.0)$ & \\
\hline Intensive care excluding CPR and intubation & $7(10.9)$ & $4(7.3)$ & $11(9.2)$ & \\
\hline Medical care & $8(12.5)$ & $3(5.4)$ & $11(9.2)$ & \\
\hline Comfort care only & $3(4.7)$ & $0(0.0)$ & $3(2.5)$ & \\
\hline Do not know & $1(1.6)$ & $2(3.6)$ & $3(2.5)$ & \\
\hline Did not do & $1(1.6)$ & $0(0.0)$ & $1(0.8)$ & \\
\hline Missing & $1(1.6)$ & $3(5.4)$ & $4(3.4)$ & \\
\hline $\begin{array}{l}\text { Overall, how satisfied were you with the material presented to you by the } \\
\text { GCD navigator or research nurse? }\end{array}$ & & & & - \\
\hline Slightly dissatisfied & $2(3.1)$ & - & - & \\
\hline Slightly satisfied & $2(3.1)$ & - & - & \\
\hline Moderately satisfied & $13(20.3)$ & - & - & \\
\hline Very satisfied & $46(71.9)$ & - & - & \\
\hline Missing/declined & $1(1.6)$ & - & - & \\
\hline How likely are you to recommend this program to others? & & & & - \\
\hline Probably would not recommend & $1(1.6)$ & - & - & \\
\hline Might recommend & $3(4.7)$ & - & - & \\
\hline Probably would recommend & $14(21.9)$ & - & - & \\
\hline Definitely would recommend & $41(64.1)$ & - & - & \\
\hline Missing/declined & $5(7.8)$ & - & - & \\
\hline
\end{tabular}


Box 1: What is different about the Plan Well Guide compared to other tools for advance care planning?

Compared to other tools that may be used to help patients near or at the end of life, our Plan Well Guide offers the following features or attributes:

- Discriminates between planning for terminal care $\mathrm{v}$. planning for serious illness

- Explains how medical decisions are made under conditions of uncertainty

- Uses a constrained values-clarification tool in which respondents have to select between competing values

- Uses grids to transparently connect stated values to respondent's preferences for medical treatments during serious illness

- Provides a decision aid on the different levels of care, with explanations about the difference between intensive care unit care, medical care and comfort care, so respondents understand the risks, benefits and outcomes of the type of treatments they are preferring

quality and quantity of GCD discussions and reduce health care costs. Further evaluation in patients making treatment decisions in a broader population and more diverse settings with longer follow-up is warranted.

\section{References}

1. Heyland DK, Dodek P, Mehta S, et al.; Canadian Critical Care Trials Group and Canadian Researchers at End of Life Network (CARENET). Admission of the very elderly to the intensive care unit: family members' perspectives on clinical decision-making from a multicenter cohort study. Palliat Med 2015;29: 324-35.

2. You JJ, Dodek P, Lamontagne F, et al.; ACCEPT Study Team and the Canadian Researchers at the End of Life Network (CARENET). What really matters in end-of-life discussions? Perspectives of patients in hospital with serious illness and their families. CMA7 2014;186:E679-87.

3. Kobewka DM, van Walraven C, Turnbull J, et al. Quality gaps identified through mortality review. BMF Qual Saf 2017;26:141-9.

4. Sharma RK, Freedman VA, Mor V, et al. Association of racial differences with end-of-life care quality in the United States. FAMA Intern Med 2017;177: $1858-60$.

5. Khandelwal N, Curtis JR, Freedman VA, et al. How often is end-of-life care in the United States inconsistent with patients' goals of care? 7 Palliat Med 2017; 20:1400-4.

6. Scheunemann LP, Ernecooff NC, Buddadhumaruk P, et. al. Clinician-family communication about patients' values and preferences in intensive care units. 7AMA Intern Med 2019:179:676-84.

7. You JJ, Downar J, Fowler RA, et al.; for the Canadian Researchers at the End of Life Network. Barriers to goals of care discussions with seriously ill hospitalized patients and their families: a multicenter survey of clinicians. 7 AMA Intern Med 2015; 175:549-56.

8. Rosenberg LB, Greenwald J, Caponi B, et al. Confidence with and barriers to serious illness communication: a national survey of hospitalists. 7 Palliat Med 2017;20:1013-9.

9. Heyland DK, Heyland R, Dodek P, et al. Discordance between patients' stated values and treatment preferences for end of life care: results of a multicenter survey. BM7 Support Palliat Care 2017;7:292-9.

10. Howard M, Bansback N, Tan A, et al. Recognizing difficult trade-offs: values and treatment preferences for end-of-life care in a multi-site survey of adult patients in family practices. BMC Med Inform Decis Mak 2017;17:164.

11. Heyland DK, Frank C, Groll D, et al.; Canadian Researchers at the End of Life Network (CARENET). Understanding cardiopulmonary resuscitation decision making: perspectives of seriously ill hospitalized patients and family members. Chest 2006;130:419-28.

12. Sudore R, Heyland DK, Lunn HD, et al. Outcomes that define successful advance care planning: a Delphi panel consensus. 7 Pain Symptom Manage 2018;55:245-55.e8

13. Légaré F, Kearing S, Clay K, et al. Are you SURE?: assessing patient decisional conflict with a 4-item screening test. Can Fam Physician 2010;56: e308-14.
14. Howard M, Bernard C, Klein D, et al. Older patient engagement in advance care planning in Canadian primary care practices: results of a multisite survey. Can Fam Physician 2018;64:371-7.

15. Sudore RL, Boscardin J, Feuz MA, et al. Effect of the PREPARE website vs an easy-to-read advance directive on advance care planning documentation and engagement among veterans. 7AMA Intern Med 2017;177:1102-9.

16. Sudore RL, Schillinger D, Katen MT, et al. Engaging diverse English- and Spanish-speaking older adults in advance care planning The PREPARE randomized clinical trial. FAMA Intern Med 2018;178:1616-25.

17. Periyakoil VS, Neri E, Kraemer H. A randomized controlled trial comparing the letter project advance directive to traditional advance directive. 7 Palliat Med 2017;20:954-65.

18. Detering KM, Hancock AD, Reade MC, et al. The impact of advance care planning on end of life care in elderly patients: randomised controlled trial. BM7 2010;340:c1345.

19. Pearlman RA, Starks H, Cain KC, et al. Improvements in advance care planning in the veterans affairs system: results of a multifaceted intervention. Arch Intern Med 2005:165:667-74.

20. Volandes AE, Mitchell SL, Gillick MR, et al. Using video images to improve the accuracy of surrogate decision-making: a randomized controlled trial. $\mathcal{F} \mathrm{Am}$ Med Dir Assoc 2009:10:575-80.

21. Myers J. Measuring quality of end-of-life communication and decision-making: Do we have this right? CMA7 2017;189:E978-9.

22. Ellis EM, Orehek E, Perrer RA. Patient-provider care goal concordance: implications for palliative decisions. Psycbol Health 2019;34:983-98.

23. Mirarchi FL, Doshi AA, Zerkle SW, et al. TRIAD VI: How well do emergency physicians understand physician orders for life-sustaining treatments (POLST) forms? 7 Patient Saf 2015;11:1-8.

24. Joseph-Williams N, Elwyn G, Edwards A. Knowledge is not power for patients: a systematic review and thematic synthesis of patient-reported barriers and facilitators to shared decision making. Patient Educ Couns 2014:94:291-309.

25. Winkler EC, Reiter-Theil S, Lange-Riess D, et al. Patient involvement in decisions to limit treatment: the crucial role of agreement between physician and patient. 7 Clin Oncol 2009;27:2225-30.

26. Mower WR, Baraff LJ. Advance directives: effect of type of directive on physicians' therapeutic decisions. Arch Intern Med 1993;153:375-81.

27. Cardona-Morrell M, Benfatti-Olivato G, Jansen J, et al. A systematic review of effectiveness of decision aids to assist older patients at the end of life. Patient Educ Couns 2017;100:425-35.

Affiliations: Department of Critical Care Medicine (D. Heyland), Kingston General Hospital; Department of Public Health Sciences (D. Heyland), Queen's University; Clinical Evaluation Research Unit (D. Heyland, R. Heyland), Kingston General Hospital, Kingston, Ont.; Bigelow Fowler Clinic (Bailey), Lethbridge, Alta.; Department of Family Medicine (Howard), McMaster University, Hamilton, Ont.

Contributors: Daren Heyland and Rebecca Heyland collected the data. All of the authors contributed to the study conception and design, data analysis and interpretation, and drafting of the manuscript, revised the article critically for important intellectual content, approved the final version to be published and agreed to be accountable for all aspects of the work.

Funding: This study was supported by grant PHE-135930 from the Canadian Institutes of Health Research.

Data sharing: None of the data are available to other researchers.

Acknowledgements: The authors thank Jennifer Korol, Laura Hoar, Marion West and staff at the Family Medical Centre and the Bigelow Fowler South Clinic and West Clinic for their support and involvement in this trial.

Disclaimer: The funder played no role in the design and conduct of the study; collection, management, analysis and interpretation of the data; and preparation, review or approval of the manuscript.

Supplemental information: For reviewer comments and the original submission of this manuscript, please see www.cmajopen.ca/content/8/2/ E289/suppl/DC1.

Editor's note: Registration of this trial was delayed until February 2018, midway through the participant recruitment period of September 2017 to October 2018. The editor is satisfied that this was an inadvertent administrative error and, in this rare circumstance, has allowed publication. See Appendix 4 (available at www.cmajopen.ca/content/8/2/E289/suppl/ DC1) for an infographic describing this study. 